\title{
A EXPERIÊNCIA DE EDUCAÇÃO POPULAR DO CENTRO POPULAR DE CULTURA EM GOIÁS ${ }^{*, 1}$
}

\author{
Maria Emilia de CAstro Rodrigues, \\ da Universidade Federal de Goiás.
}

\begin{abstract}
Resumo: O presente artigo aborda a ação do Centro Popular de Cultura em Goiás (CPC-GO) na educação de adultos, nos anos 1960. Trata-se de um movimento de educação popular, organizado pela União Nacional dos Estudantes (UNE), com forte atuação de estudantes secundaristas e universitários, intelectuais, artistas em atividades culturais de conscientização e no processo de educação de adultos, no estado de Goiás. Ele revela como os militantes deste movimento em Goiás tiveram forte influência do Movimento de Cultura Popular de Recife, no processo de alfabetização de adultos, o que gerou inclusive a elaboração de um livro de Leitura para Adultos. O texto advém de pesquisa de doutorado, construído com análises documentais, entrevistas, depoimentos e relatos de militantes do movimento daquele período.
\end{abstract}

Palavras-chave: Centro Popular de Cultura em Goiás. Educação Popular. Educação de Jovens e Adultos. Educação popular.

A Educação Popular em Goiás nos anos 1960 foi muito intensa, destacando-se os trabalhos desenvolvidos pelo Centro Popular de Cultura de Goiás (CPC-GO), Instituto de Cultura Popular de Goiás (ICP) e Movimento de Educação de Base em Goiás (MEB-GO). Neste artigo abordaremos a experiência do CPC em Goiás, que contribuiu significativamente na educação de adultos (EDA) no período de 1961 a 1964, com seu trabalho de conscientização e alfabetização de adultos, e foi fortemente influenciado pelo MCP, em especial pela contribuição de Paulo Freire e sua equipe ao processo de alfabetização de adultos. 


\section{SitUANDO O PERÍODO}

O II Congresso Nacional de Educação de Adultos, realizado em 1958, apontou para a necessidade de rediscussão das formas e do conteúdo da EDA, e destacou o direito de todos a uma escolarização efetiva. Nele houve críticas às campanhas de educação de adultos das décadas de 1940/1950, que, além de não cumprirem as promessas de erradicação do analfabetismo, de continuidade dos estudos para os adultos e da melhoria nas condições de vida dos que conseguiam acesso à escola, utilizavam-se de metodologia e materiais distantes da realidade dos adultos. Isso gerou insatisfação frente às promessas dos benefícios do desenvolvimentismo industrial.

Em função da insatisfação de vários setores com as campanhas governistas, que imprimiam uma visão utilitarista e caritativa à EJA, diferentes iniciativas surgiram e se encontraram no "Il Congresso Nacional de EDA", em 1958, o qual refletiu as contradições, divergências e ambiguidades existentes entre os vários movimentos populares que atuavam com a EDA e os organismos governamentais. O Congresso foi um marco rumo à transformação das idéias educacionais brasileiras, e trouxe um novo conceito antropológico de cultura - que ao ser difundido gerou uma nova imagem do analfabeto, como um homem capaz e produtivo, responsável por grande parte da riqueza da nação - além de reintroduzir as reflexões sobre o social, propiciando vínculos entre educação e consciência política. A sociedade foi conclamada a participar do processo de alfabetização dos adultos. (RODRIGUES, 2000, p. 10-11)

O II Congresso trouxe uma mobilização intelectual e a intensificação da luta política e ideológica, presente nas 210 teses discutidas. Entre outros, o trabalho de Paulo Freire apresentou-se como alternativa para a superação do conceito de alfabetização como mera decodificação, articulando-o com o ato político de leitura do mundo, da "palavramundo", no qual o educador e o educando são vistos como sujeitos ativos da história, da cultura e do processo ensino-aprendizagem, rumo a sua humanização. Paulo Freire criticou a educação tradicional, que via o analfabeto como ignorante, uma gaveta vazia na qual o educador depositava conhecimentos, e propôs uma EDA em que homens e mulheres fossem considerados possuidores e produtores ativos da cultura, numa proposta dialógica de educação, compreendendo a produção de conhecimentos como ato coletivo e processual, pautada em conteúdos vivos, dinâmicos, inseridos no cotidiano dos sujeitos envolvidos. Uma ação educativa que não negasse a cultura das classes populares, mas que a valorizando e desenvolvendo novos conhecimentos, através do diálogo, ${ }^{2}$ favorecesse a passagem da consciência ingênua ou intransitiva, que 
os homens possuem, para a consciência crítica, necessária ao engajamento ativo para a transformação social. Segundo Góes (1980, p. 46),

[...] os pernambucanos convocavam no segundo Congresso a um trabalho educativo com o homem e não para o homem; a substituição da aula expositiva pela discussão; a utilização de modernas técnicas de educação de grupos com a ajuda de recursos audiovisuais etc.

Era um período de efervescência política, econômica e cultural, em âmbito nacional e internacional, intensamente vivido em Goiás, em decorrência da visão que se tinha daquele período pré-revolucionário. Esse contexto de grande mobilização e envolvimento se explicitava não apenas nas músicas por eles criadas e cantadas, nas peças de teatro apresentadas em praças públicas nas carrocerias de caminhões, mas também nas greves e manifestações organizadas, entre outras ações efetivadas. O grande tema da época era o imperialismo e a ele se contrapunha o nacionalismo. Buscava-se a afirmação da identidade cultural e a democratização da cultura nacional.

Nesse amplo quadro de mobilização social encontrava-se também o Estado de Goiás, cujo governo apoiou os estudantes e as camadas populares na busca de participação política, visando essencialmente à organização dos trabalhadores rurais. $\mathrm{O}$ apoio de Mauro Borges perpassou desde a criação da associação de lavradores e sindicatos, a criação do ICP-GO, com vistas a estreitar a vinculação governo-povo - entre outras ações, financiando a ida de estudantes do CPC e do ICP-GO ao Recife, para aprender com Paulo Freire e sua equipe o novo método de alfabetização-, até o apoio técnico-financeiro aos encontros de trabalhadores rurais e de estudantes.

Naquele período, como a escola oficial era distante da vida e do mundo do trabalho, autoritária, conservadora e marginalizadora da grande maioria da população brasileira, os movimentos populares buscaram construir fora da escola a educação popular de adultos, que proporcionasse o acesso do povo ao processo educativo. Este posicionamento apontava para uma perspectiva de educação popular produzida pelas classes populares, ou por grupos/instituições a elas vinculadas, de acordo com os interesses dos trabalhadores - uma pedagogia dos oprimidos. Portanto, foi neste cenário de descontentamento e de busca de alternativas que se inseriram os movimentos populares de educação e cultura da década de 1960.

OS MOVIMENTOS DE EDUCAÇÃO POPULAR

Nessa conjuntura surgiram, ligados a instituições da sociedade civil, dentre outros movimentos: o MCP criado em 1960 por estudantes, artistas 
e intelectuais pernambucanos, que concretizavam projetos oriundos de grupos de profissionais liberais, em busca de um ideal político, o de alfabetizar e possibilitar a conscientização do povo brasileiro, ao qual se vinculava o Sistema Paulo Freire do MCP de Recife/Pernambuco; o CPC ligado à União Nacional dos Estudantes (UNE).

Originados na sociedade política foram criados: a Campanha de Pé no Chão Também se Aprende a Ler (1961), no Rio Grande do Norte; e o Plano Nacional de Alfabetização (PNA) do Ministério de Educação e Cultura (1963), que contou com a participação de Paulo Freire, a convite do Ministro da Educação, Paulo de Tarso Santos, para coordenar o Plano e realizar a Campanha Nacional de Alfabetização, tendo sua proposta políticopedagógica como norteadora do trabalho. E na conjugação de esforços da sociedade política e civil, destacamos a Campanha de Educação Popular (CEPLAR), na Paraíba; e o MEB, uma iniciativa da Igreja Católica, criado pela CNBB, em 1961.

A educação popular era extremamente vinculada à cultura popular e ao processo de conscientização do povo. Cultura compreendida por estes movimentos como o conjunto dos modos de ser, de viver, pensar e se expressar de um agrupamento social humano, historicamente produzido. Perspectiva que compreende o homem como ser incompleto, que necessita do outro para se ver como tal, o que o põe em contato com outros homens no campo da sociabilidade historicamente situada, possibilitando-lhe se constituir.

Cultura popular elaborada pelas e/ou com as camadas populares ao longo de sua vivência, enquanto expressão de sua história, de seu modo de ser, agir, pensar e expressar o mundo, a si mesmas, e as relações que estabelecem com o mundo, nas quais produzem saberes, valores, crenças e visão de mundo do povo, muitas vezes manipulada pelos interesses dominantes, favorecendo o velamento da realidade.

Assim, Maria da Conceição B. Rapôso (1985) afirma que é a cultura popular "o ponto de partida para a superação do senso comum que lhe é inerente e aqui deve ser considerado um ponto de apoio estratégico para no seu seio articular e veicular uma ideologia historicamente necessária" (p. 20). Essa ideologia possibilita organizar os trabalhadores, formando o terreno no qual os homens se movimentam, adquirem consciência de sua posição e lutam pela transformação da realidade social. Mas é importante acentuar que o respeito à cultura popular, pelos intelectuais comprometidos com a classe trabalhadora, pressupõe a elevação cultural, ética e política das massas, o que passa por um processo educativo histórico-crítico. 
É nesta perspectiva que veremos o CPC-GO e a influência que recebeu do MCP de Pernambuco, no qual se inseria a proposta de Paulo Freire, um dos movimentos de alfabetização de adultos que influenciou sobremaneira os demais movimentos de educação popular nos anos 1960.

\section{O Centro Popular de Cultura de Goiás}

OCentro Popular de Cultura foi criado em 1961, no Rio de Janeiro, pela UNE, a partir do Teatro de Arena de São Paulo. Em âmbito nacional estendeuse para 12 estados, dentre eles Goiás, com a primeira UNE-Volante; em 1963 se consolidou nacionalmente com a segunda UNE-Volante. Inicialmente propunha favorecer a conscientização do povo por meio da cultura popular revolucionária, com peças de teatro, e demais atividades culturais (filmes, música, literatura, edição e distribuição de livros etc.), reuniões e discussões, envolvendo estudantes, intelectuais e artistas e, posteriormente, por meio da educação de adultos. Os CPCs eram autônomos em seu funcionamento e organização. É o que ocorria em Goiás.

Os Centros Populares de Cultura foram muito fortes em Recife, em Natal e em Goiânia [...]. Um samba composto pela Betinha [Elizabeth Hermano] traduz em grande medida nosso ideário de revolução:

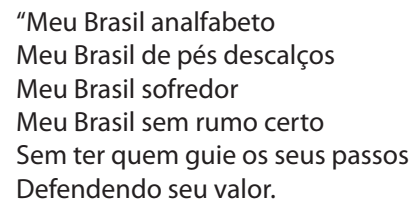




\author{
E a toda burguesia \\ Grita o João, grita a Maria \\ Chega de exploração \\ Nesta luta destemida \\ Daremos a própria vida \\ Em prol da revolução. \\ Virá o homem do campo \\ Virá o homem da cidade \\ Virá o operário, o camponês e o estudante \\ Juntos pela liberdade".
}

A gente defendia com veemência o voto do analfabeto, fazia poesia sobre isso, [...] peças de teatro [...]. Foram vários momentos de discussão política na Vila Nova, na Fama, na Vila Operária [...] a gente pintava e bordava com toda essa coisa da cultura popular. [...] eram [...] atividades mobilizadoras de debates, em vários níveis [...] que a gente levava nas apresentações, nos bairros, com a participação dos operários também como atores. (CUNHA, $31 / 5 / 2001$, palestra)

O CPC de Goiás, composto por estudantes secundaristas e universitários (ligados à União Estadual dos Estudantes (UEE) e à UNE) desenvolveu atividades como "peças de teatro políticas" - encenadas ora em carrocerias de caminhão nos diversos bairros de Goiânia, ora nas escadarias do Teatro Goiânia, entre outros espaços -, debates sobre cultura brasileira e democratização da cultura, realidade brasileira, palestras etc., pois via a cultura como portadora de uma importante função social e instrumento de conscientização, politização e diversão.

Por causa do intercâmbio de informações entre os vários movimentos e de pessoas que atuavam em vários deles ao mesmo tempo, percebeu-se que, pelo processo de alfabetização, numa perspectiva crítica, se poderia contribuir com o processo de conscientização do povo brasileiro, o que passou, após uma revisão, a ser uma diretriz política do movimento. Em setembro de 1962, a UNE lançou sua "Campanha de Alfabetização de Adultos", incluindo esta área como uma das principais do movimento estudantil, na luta contra o subdesenvolvimento, a miséria, a fome e pelas reformas básicas. Segundo essa concepção, os operários e camponeses aprenderiam a ler e a escrever, analisando e criticando a realidade em que se inseriam.

Entre outras ações, o CPC-GO utilizou-se do processo de alfabetização de adultos em espaços ociosos da Pontifícia Universidade Católica de Goiás (PUC-Goiás), ${ }^{3}$ à época Universidade Católica de Goiás; da Universidade Federal de Goiás (UFG); Igrejas etc. Participavam da alfabetização de adultos, pelo movimento estudantil, além de Alda Maria Borges Cunha e Maria José Jaime, Nei Rocha Cunha, José Pereira Peixoto Filho, Elizabeth Hermano, entre outros 
estudantes da UNE e UEE. Esse Movimento em Goiás foi influenciado pelo Movimento Popular de Cultura (MCP), como veremos a seguir.

\section{A influênCia advinda do MCP e do Sistema Paulo Freire ao CPC de Goiás}

Em 1962 Alda Maria Borges e Elizabeth Hermano (Betinha), membros do CPC-GO, participaram, durante 15 dias, de um curso, juntamente com outros estudantes, no MCP de Recife, assistindo aulas, explicações do próprio Paulo Freire e sua equipe e realizando visitas nos círculos de cultura. A esse respeito, Alda Cunha relatou:

[...] em 62 eu vou [...] a Recife, conhecer [...] Paulo Freire, e [...] uma nova forma de alfabetizar. [...] Nós somos cinco universitários, enviados pelo governo de Goiás pra conhecer [...] o trabalho de Paulo Freire. [...], recebendo aulas e instruções do próprio Paulo Freire e da sua equipe, visitando as salas de alfabetização de adultos, vendo aquele trabalho sendo feito com o projetor de slide, vendo as fichas de cultura [...] (CUNHA, entrevista, ${ }^{4}$ 20/9/2006).

A experiência do Sistema Paulo Freire foi desenvolvida inicialmente no Centro de Cultura Popular do MCP Dona Olegarina, no Poço da Panela, em Recife e posteriormente aprofundada no Serviço de Extensão Cultural $(\mathrm{SEC})^{5}$ da Universidade do Recife, sendo sistematizada inicialmente no artigo "Conscientização e Alfabetização - uma nova visão do Processo", publicado inicialmente em brochura [1962]. Em seguida, ele se juntou a artigos de sua equipe - Carlos Augusto Nicéias, Jarbas Maciel, Aurenice Cardoso da Costa, Elza Freire, Jomard Muniz de Brito e demais componentes do SEC -, e foram organizados na Revista Estudos Universitários, da Universidade de Recife, em 1963. Esta experiência influenciou os movimentos do início da década de 1960, devido ao intercâmbio de informações entre eles. Isso possibilitou, apesar de algumas divergências, um trabalho dentro de uma base comum de princípios e orientações metodológicas: a forma positiva de ver o analfabeto, o aspecto da conscientização e organização política das massas e o processo de gestão.

Foram desenvolvidos conceitos e concepções (de trabalho, liberdade, práxis, conscientização, diálogo, educação bancária e libertadora etc., vinculados a uma pedagogia do oprimido) tão caros a Paulo Freire e a sua equipe, profundamente influenciados pela concepção de homem, mundo e sociedade.

Paulo Freire [1962] mencionou ser o homem, na pluralidade de relações que estabelece com e no mundo natural e cultural, no qual se acha inserido, capaz de discernir a tridimensionalidade do tempo, criando e recriando, 
integrando-se às condições de seu contexto, respondendo aos desafios desse mundo, auto-objetivando-se. Ao fazer isso transcende esse mundo, altera-o e altera-se, testa, escolhe a melhor resposta, age, no domínio da história e da cultura. É um ser no mundo e com o mundo, que nele se enraíza e temporaliza, um ser situado e datado, um ser livre. Contudo, toda vez que sua liberdade é cerceada passa a ser um ser acomodado, ajustado, passivo. “É porque se integra, na medida em que se relaciona - e não apenas se acomoda - que o homem cria, recria e decide" (FREIRE, [1962], p. 4).

Por meio dessas relações o homem dinamiza o mundo, temporaliza os espaços geográficos, fazendo cultura, num jogo dialético de relações em que marca o mundo e é por ele marcado, transformando-o e transformandose; ao fazê-lo vão se conformando as épocas históricas e, pelo trabalho, o homem participa destas épocas. "E o faz melhor toda vez que, integrando-se ao espírito delas, se apropria de seus temas fundamentais, reconhece suas tarefas concretas" (FREIRE, [1962], p. 5). Nesse processo é fundamental uma permanente atitude crítica, por meio da qual o homem poderá integrar-se, "à proporção que seus temas são captados e suas tarefas resolvidas" (FREIRE, [1962], p. 5).

Paulo Freire viu na educação uma possibilidade de contribuir, como ato político, para a formação da consciência crítica do povo, que, ao refletir sobre a realidade social, apropriando-se de ferramentas culturais, transforma coletivamente as estruturas sociais. Uma pedagogia libertadora, que passa(va) pela Antropologia Cultural, propiciando aos analfabetos instrumentos que os integrassem a uma nova sociedade que se anunciava.

Para ele, entre outros aspectos, devido ao colapso da hegemonia de classe, a sociedade brasileira dos anos 1960 havia rachado, e vivia um processo de abertura, pela perda de equilíbrio das forças que a mantinham. Apresentava-se, então, como desafio fundamental construir uma sociedade aberta, democrática, em que o povo atuasse ativamente na história, não mais imerso no processo, mas emergindo e participando dele, superando a aparente crise que se instalara, pelo choque das velhas formas com o novo.

Cabia, portanto, contribuir para que o povo avançasse da consciência intransitiva ou transitivo-ingênua, para a transitivo-crítica, inserindo-se criticamente no processo. Daí a necessidade de uma educação crítica, que buscasse soluções com o povo e não para ele, para a realização das reformas básicas, como buscou fazer os movimentos, entre eles o CPC goiano.

Essa pedagogia, cujo compromisso ético-político-filosófico e religioso com os trabalhadores toma a luta pela liberdade dos/com os oprimidos, contra o sistema que lhes oprime, parte da análise crítica da realidade social como grande desafio. Como pedagogia do oprimido, é construída na contradição 
opressores-oprimidos e na situação concreta de opressão; uma pedagogia que compreendia que os homens se libertam coletivamente nas relações que estabelecem entre si e com o mundo.

Esta pedagogia tomava o analfabeto como sujeito que possui saberes existenciais, apreendendo a realidade de forma preponderantemente sensível e mágica, no âmbito do senso comum e/ou bom senso, de modo a obter instrumentos para organizar seu pensamento de forma crítica; que vive um tempo e espaço capaz de impor situações desafiadoras, as quais são captadas e expressas verbalmente. Uma pedagogia que percebia a educação numa relação dialética com a cultura; que libertava pela conscientização e politização, ao possibilitar não só a alfabetização, mas a tomada de consciência de sua responsabilidade social e política.

Dessas reflexões adveio, na EDA, uma metodologia ativa, dialógica, motivadora e crítica, que perpassava o levantamento do universo vocabular do grupo a ser alfabetizado; a seleção, neste universo, das palavras geradoras; a criação/representação de situações existenciais do grupo a ser alfabetizado; a criação de fichas-roteiro, as quais auxiliavam os coordenadores dos círculos de cultura nos debates; a elaboração de fichas com as famílias fonêmicas das palavras geradoras decompostas - denominadas de "fichas de descoberta" - a partir do quê o analfabeto descobria a formação vocabular, por meio da combinação de fonemas e sílabas, criando palavras, frases, textos.

Paulo Freire (1963, p. 32) dizia que"na alfabetização de adultos o que temos que fazer é levá-los a conscientizarem-se para que se alfabetizem", pois para a transformação social é fundamental a politização, a qual passa pela opção - já que ninguém politiza ninguém, é nas relações que estabelecem com o mundo e com os outros homens que podem se politizar. Daí ser fundamental um método que ajude os homens a se conscientizarem dos problemas que os circundam, que os instrumentalize criticamente para optarem.

Para a construção do programa do curso de alfabetização, iniciava-se no contato direto com a comunidade a pesquisa do seu universo vocabular. Pesquisava-se o que eles pensavam, como viviam, o que desejavam ser, os desafios e dificuldades vividos, o grau de criticidade, questionando por exemplo, se acreditavam em mal-assombrado, caipora e lobisomem; registrava-se ainda a idade, a profissão, sua opinião sobre o processo de alfabetização; e, também, as sentenças, expressões e palavras mais usadas, "sobretudo as mais carregadas de emoções. [...] Esse primeiro contato é [...] relevante porque vamos colher o material, que será organizado, para posteriormente ser-lhes devolvido como um dos veículos de sua educação, através de debates" (CARDOSO, 1963, p. 73). As sentenças obtidas, além de 
utilizadas como objeto de estudo, faziam parte dos pequenos jornais que circulavam entre os educandos. Além disso, os dados obtidos na pesquisa facilitavam a interação e a compreensão entre as pessoas nos Círculos de Cultura. É o que afirma Aurenice Cardoso (1963, p. 73):

Enfatizamos esses dados obtidos, porque não acreditamos que um material vindo de fora, importado de outras regiões, carregado de interesses que não os daquela população, distante dos problemas, da vida e da condição dos adultos possa ser eficaz.

É convicção nossa que dialogando com os analfabetos seus problemas possam eles se tornar mais críticos. Por isso é o diálogo a técnica fundamental, o qual coloca os analfabetos como participantes.

Só o diálogo leva o homem a reflexivamente se tornar responsável. E esta responsabilidade se incorpora ao homem de maneira vivencial.

Da pesquisa do universo vocabular, eram selecionadas as palavras geradoras - "palavras chave que, decompostas em seus fonemas, propiciam o surgimento de novas pela combinação daqueles" (CARDOSO, 1963, p. 73). A escolha dessas palavras considerava o critério de riqueza fonêmica da língua portuguesa e a pluralidade de engajamento ${ }^{6}$ na realidade local, regional e nacional a serem dominadas pelos analfabetos, de maneira que, uma vez vencidas, podiam ler qualquer texto a que tivessem acesso. Cada palavra geradora era representada por uma imagem que ora se associava ao objeto, ora à situação existencial a que se referia.

Todo esse processo de pesquisa do universo vocabular e seleção de palavras geradoras foram empreendidos em Goiás, quando da elaboração do Livro de Leitura para Adultos, e posteriormente, na Campanha de Alfabetização em Goiás, pelo Plano Nacional de Alfabetização (PNA), e na elaboração do Conjunto Didático Benedito e Jovelina do MEB-Goiás.

As atividades do Círculo de Cultura iniciavam-se com a discussão sobre o conceito antropológico de homem, trabalho e cultura. Para estas discussões foram elaborados onze cartazes, com imagens que expressavam ser a cultura toda a criação humana, seu modo de ser e de se comportar, a partir da representação de situações existenciais.

Era uma concepção de trabalho e cultura que tomava o homem no mundo e com o mundo, natural e cultural. $\mathrm{O}$ analfabeto descobrindo-se como fazedor deste mundo de cultura, pelo trabalho. Esse conceito de trabalho ${ }^{7}$ tinha uma grande centralidade e era amplamente utilizado por Paulo Freire nos Círculos de Cultura. Segundo Cardoso,

[...] iniciado nas atividades pela discussão do que é cultura e mais adiante dialogando a respeito de problemas vitais e sociais, sente o analfabeto além 
de profundamente motivado, desinibido, inclusive pela dimensão nova que adquire de ser capaz de criar. Torna-se autoconfiante e comporta-se já diferentemente. (1963, p. 76)

Nos Círculos de Cultura apontava-se a cultura como aquisição/produção humana, a qual numa sociedade letrada não se faz apenas via oral. Em seguida passavam ao debate sobre a democratização da cultura e, posteriormente, à utilização de diafilmes com situações reais daquela comunidade, os quais eram decodificados pelos educandos, juntamente com o educador.

Nesse processo, o homem era visto como sujeito do processo de conhecimento, da história, e não como objeto. Porém, na sociedade capitalista, o trabalho, que deveria ser fonte de realização humana, apresentase como fonte de alienação, passa a ser fonte de desumanização; o trabalhador deixa de se reconhecer no fruto de seu trabalho, não reconhecendo a si e aos outros homens, que ali depositaram sua força produtiva. Assim, o trabalho alienado não possibilita ao homem o desenvolvimento de suas capacidades, como formação omnilateral. Também, cada vez mais se busca um lucro maior, subtraindo-o do salário do trabalhador, bem como do aumento da produtividade, em geral resultado de um aumento da jornada de trabalho e/ ou da automatização. Decorrem desse processo a opressão e a expropriação maior do trabalhador, que se vê forçado a trabalhar mais, sem receber sequer para suprir suas necessidades básicas de subsistência.

Trabalhadores cada vez mais explorados, que não vivem uma vida digna, ao se conscientizarem criticamente desse processo de exploração e desumanização, adota instrumentos de luta para sua superação/contraposição coletiva, organizando-se em sindicatos e outras formas de intervenção coletiva para a transformação da realidade.

Essa discussão, partindo do valor pragmático primário ou da "pragmática existencial concreto-sensível-vegetativa" (MACIEL, 1963b, p. 61), avançava sucessivamente para outros níveis da pragmática: a existencial geográfica, a existencial-social (passando pelos subníveis: conhecimento empírico, conhecimento técnico, conhecimento científico, conhecimento filosófico e estético), a existencial-transitiva.

Vivendo num sistema opressivo, Paulo Freire (1967) alertou para o medo que os trabalhadores têm da liberdade, sentimento que se liga a uma não consciência crítica da sua alienação do trabalho. E, por permanecerem aderidos ao capitalista, devido a"hospedarem em si" o opressor, os trabalhadores não veem em si esta consciência opressora e tampouco têm a consciência da situação estrutural que a produz. A busca de superação desta condição de oprimido passa, entre outros aspectos, pela necessidade de os oprimidos 
distanciarem-se e debruçarem-se criticamente sobre a contraditória condição de opressor-oprimido na realidade historicamente situada, apercebendo-se da sua condição estrutural e superando o "medo da conscientização".

Foi o que tanto o MCP e o CPC-GO buscaram fazer. E aqui se insere a importância da construção de uma pedagogia libertadora dos oprimidos, em que os trabalhadores, juntamente com aqueles que se comprometem com eles e com sua luta, superem a pedagogia bancária (desvinculada da realidade social, opressora, que toma o educando como tabula rasa e sobre o qual imprime ideologicamente sua concepção) e avancem ultrapassando o senso comum, após nele pautar a construção de uma sociedade de homens que se libertam e, nesse processo, coletivamente humanizam-se.

Essa alfabetização de adultos se processava por um método visto por Paulo Freire como de tendência eclética, centrada no aluno, e "[que] abarca exatamente a síntese e a análise [...] inclusive com a elaboração de textos em colaboração com os alunos" (1963, p. 27). Segundo as palavras de Aurenice Cardoso (1963, p. 76) tratava-se de "um método analíticosintético, o da palavra-ação, que nos parece vem sendo bastante eficaz na alfabetização de adultos. [...] Nele, são empregados processos que partem do todo, decompondo-o em partes, para posteriormente recompô-los no todo". Um método que considerava no aspecto psicológico o sincretismo e a globalização no ensino, como capacidade que possuímos de reter o todo, antes dos detalhes. Outro fator de aprendizagem era o interesse que a palavra geradora despertava no grupo, partindo de algo conhecido para o desconhecido, o que facilitava o processo, por ter uma significação para os participantes.

O coordenador de debates do Círculo de Cultura, após promover o diálogo no grupo a partir das fichas de cultura, ao entrar no trabalho com as palavras geradoras, não só desafiava os educandos a descreverem o que viam, mas a fundamentar suas opiniões em bases mais críticas, indagando por quê?, para quê?, onde?, como? Ou seja, proporcionando que a realidade local, reapresentada pela ficha, fosse associada à realidade "regional e nacional, debatendo aspectos econômicos, sociais, políticos, sanitários etc., a que as fichas ofereçam oportunidade. Esse debate deve dinamizar todo o grupo, levando todos a se expressarem mais racionalmente" (CARDOSO, 1963, p. 77).

Concluído o debate, voltava-se para a palavra escrita na ficha, associando-a e direcionando a visualização do vocábulo. Em seguida apresentava-se outra ficha em que aparecia a palavra isolada, visualizando-a como um todo. Segundo Cardoso (1963), esse processo se dava de "uma forma estrutural e orgânica, uma gestalt. Na compreensão da gestalt da aprendizagem, os gestaltistas acentuam 'a percepção de relações, 
a consciência das relações entre as partes e o todo, dos meios com as consequências"' (p. 77).

Após a visualização, introduzia-se o grupo na decomposição da palavra geradora em sílabas, apresentando uma ficha com a palavra cujas sílabas estavam separadas. De cada sílaba da palavra levava-se, uma a uma, a conhecer toda a família fonêmica; era importante que os alfabetizandos reconhecessem as sílabas da palavra geradora. Comparavam na família silábica as semelhanças e diferenças, notando que começavam iguais e se diversificavam no final; ouvia-se o nome de cada sílaba e fazia-se a leitura de diversas maneiras das mesmas. Em seguida, todas as famílias apareciam juntas em uma mesma ficha: a partir da qual faziam a leitura na horizontal, vertical, de cima para baixo e vice-versa. Esta ficha permitia aos educandos observarem que as sílabas de cada coluna iniciam diferentes e terminam iguais. Ocorria então a decomposição da sílaba em letras, informando-se o nome das mesmas. Também este quadro, denominado ficha da descoberta, permitia aos alfabetizandos descobrirem novas palavras.

Segundo Cardoso (1963), as noções gramaticais eram introduzidas à medida que surgiam as oportunidades e desde o início recebiam "palavras e sentenças por eles formadas, batidas à máquina ou mimeografadas, para que se identifiquem com a letra de imprensa" (p. 78). E salientou que "jornais são circulados, lidos e debatidos; pequenas composições, poemas e bilhetes são escritos" (p. 78).

É importante destacar que, em função da repercussão do processo de alfabetização realizado por Freire e sua equipe, várias pessoas de outros movimentos de educação popular da época foram conhecer in loco o trabalho por eles realizado, como o fizeram os militantes do CPC-GO e do ICP de Goiás, dentre eles Alda Maria Borges Cunha e Elizabeth Hermano.

[...] O trabalho de Paulo Freire nos dá um lastro pra chegar em Goiânia, e dentro do movimento estudantil [...], fazermos essa experiência em Goiânia. Nós achamos que seria interessantíssimo no trabalho de alfabetização de adultos, que já realizávamos, [...] fazer um livro de leitura que pudesse ser utilizado na alfabetização. Esse livro de leitura é feito em 1962, e [...] não é datado, aquela distração nossa. É feito dentro de todo um viés do Centro Popular de Cultura de Goiás, e nós registramos, "com orientação técnica do Movimento de Cultura Popular do Recife", e com todo embasamento daquilo que a gente viu com o trabalho de Paulo Freire. (Alda, entrevista, 20/9/2006)

Imbuídas da fundamentação do Sistema Paulo Freire, ${ }^{8}$ em especial da experiência de alfabetização, e diante da necessidade de usar algum suporte de leitura na EDA, Alda Maria Borges e Maria José Jaime (Bisé) elaboraram 
o Livro de Leitura para Adultos, uma produção do CPC-GO, sob orientação técnica do MCP do Recife, e apoio da Reitoria da UFG; do Diretório Acadêmico Estudantil (DCE), da UFG; do diretor e funcionários da oficina de Imprensa Universitária da UFG; técnicos do Serviço Áudio-Visual e Documentário (Savid) da UFG, que executaram as fotografias; da Secretaria de Educação e Cultura de Goiás (SEC-GO) e do ICP-GO do CERNE. O apoio do ICP-GO e da SEC-GO, órgãos do governo estadual, veio do Secretário de Educação do governo Mauro Borges, para a reprodução dos exemplares, considerando-se que o material seria importantíssimo para a alfabetização de adultos em Goiás.

O MATERIAL DIDÁTICO DE EDA PRODUZIDO PELO CPC DE GOIÁS

Para a produção do Livro de Leitura para Adultos, as autoras seguiram a proposta de Paulo Freire. A capa foi desenhada pela artista plástica Maria Guilhermina; a primeira lição se iniciava com as palavras geradoras "povo" e "voto", seguidas da frase "O voto é do povo" (BORGES; JAIME, [1962] p. 3), carregadas de significado e problematizadoras para o contexto histórico do início da década de 1960, quando se lutava pelo direito do voto do analfabeto, o acesso de todo o povo na escolha de seus representantes, com movimentos que enfatizaram a importância da cultura popular e sua difusão, bem como da educação e da conscientização da população adulta analfabeta. A lição tinha o seu desdobramento no cartaz de descoberta, palavras novas e frases a partir das palavras geradoras iniciais.

Na sequência apareciam as palavras geradoras "vida e saúde"; "fome e pão"; "casa e roça"; "operário, barraco e cidade"; "escola"; "Brasil, Petrobrás, livre"; "Goiás, homem e progresso"; "campo e sertanejo"; "colheita, enxada e fazenda"; "paz"; "chagas"; "dinheiro, privilégio"; "folclore, ritmo"; "democracia e fraternidade", entre outras, sempre seguidas de frases em que se utilizavam as palavras geradoras problematizando a realidade social daquele momento. Além disso, o livro trazia fotos da realidade social, problematizando, tanto com palavras como com imagens, as contradições sociais, presentes, por exemplo, na forma da moradia: ao lado da palavra "casa", aparecia uma residência luxuosa de Goiânia em contraposição à palavra "barraco", cuja foto trazia moradores em frente a seus barracos de lona no Setor Universitário, à época, uma área de ocupação da capital. A partir da 45a lição os textos eram cada vez maiores e mais densos. Entre eles, cabe destacar:

Os Direitos do Homem (lição 74), [...] representativo das discussões do início da década de 60 quando os movimentos populares como o CPC-GO [...] apontavam para a construção de uma sociedade mais justa; 
A Sindicalização (lição 75) [...] lição [que] vem logo após a discussão dos direitos do homem e traz à tona a necessidade de união, via sindicato, para que o trabalhador se fortaleça para lutar por seus direitos;

Foto que apresenta o trabalhador urbano ao lado das palavras geradoras "dinheiro" e "privilégio" (Lição 54) [...]. Na sequência há um texto que fala do dinheiro como resultado do trabalho humano, da sua utilização para manter as necessidades básicas dos homens e remete à questão da apropriação por poucos (enquanto privilégio) do que foi produzido pelo trabalho de muitos, suscitando a conscientização do trabalhador da sua condição de explorado pelo sistema capitalista.

Foto de uma pequena moradora do Bairro Universitário em Goiânia-GO, ao lado do texto Justiça e Paz (Lição 80) do Livro de Leitura para Adultos. Esta lição fala do Brasil como um país cheio de problemas, cujas soluções podem ser encontradas se a voz do povo for ouvida. Ele finaliza dizendo " $\mathrm{A}$ paz nasce da justiça". (http://fe.ufg.br/museu/memoria_viva_meb_5.html, vídeo. Acesso em: 20/02/2007).

Além da poesia da lição 73, "O voto do analfabeto", de autoria de Nei Rocha Cunha, num momento em que o analfabeto não tinha direito ao voto, reafirmavam-se argumentos como: os homens são iguais; possuem os mesmos direitos, inclusive o direito à educação; esse analfabeto era um homem tão capaz quanto qualquer outro homem: trabalha, paga impostos, taxas etc.; conhece a realidade e necessidades do povo, era honesto e responsável; portanto tinha direito ao voto "pra escolher bem os homens/ Que vão fazer as leis todas/Que são pra ele também" (apud BORGES; JAIME, [1962], p. 91-92). Segundo Alda Borges, em entrevista já citada, estes eram os argumentos, na verdade, "que pautavam as nossas discussões no movimento estudantil".

Nesta entrevista, Alda Borges Cunha, uma das autoras do livro avalia:

[...] só recentemente é que eu percebo uma coisa curiosa nesse livro de leitura, ao preparar essa nossa entrevista, aqui agora. É que a palavras geradoras são apresentadas no nosso livro de leitura, e nós vamos fazer uma coisa, que Viver é lutar vai fazer depois, que é colocar indagações no final de cada texto: ao invés de se fazer só afirmações, se indaga. Então nós temos a palavra geradora "vida", "saúde", e a pergunta no final: "O povo tem saúde?" Nós vamos fazer afirmações sobre "o povo tem fome", "o pão dá saúde ao povo", mas também perguntamos: "Eu sou são?" E são essas questões, ampliando o debate dessas palavras geradoras, que eu considero um achado nesse livro. Com as indagações que a gente viu acontecer nos círculos de cultura, a gente julgou que num livro de leitura, também seria uma boa idéia, afirmar, 
sim, algumas coisas, mas indagar outras tantas. E o nosso livro de leitura é pautado por esse tipo de metodologia. (20/9/2006)

É, portanto, um livro que contempla a proposta freiriana, não apenas na metodologia do trabalho com temas geradores, mas na sua estrutura e forma de organização, trazendo para o interior das leituras, discussões e propostas de escrita sobre o conteúdo social vivido naquele momento. Alia-se a essa proposta, também pelas reflexões feitas a partir das leituras, estudos e ações empreendidas pelos estudantes e participantes de movimentos estudantis e religiosos, bem como pelas opções político-ideológicas das autoras, frente à perspectiva de construção de uma sociedade mais justa, mais humana, verdadeira, fraterna e passível de ser transformada - pelos homens construída, por eles pode ser mudada.

O Jornal 4०PODER (25/8/1963, p. 1), que circulava na época, destacou em manchete: "CARTILHA DO CPC DESPERTARÁ POVO PARA OS PROBLEMAS AGRÁRIOS" e afirmou que o Livro de Leitura para Adultos era

pouco diferente da cartilha elaborada pelo MCP pernambucano, elogiada pelas mais categorizadas autoridades educacionais brasileiras, entre elas, $\mathrm{O}$ professor Anísio Teixeira, atual Reitor da Universidade de Brasília, "a do CPC goiano"'sublinha os contrastes da realidade goiana, provocando, mesmo ao leitor menos consciente, a perquirição das causas dos próprios problemas, 0 que envolve e desperta, afinal, o interesse para o extenso axioma brasileiro.

Este Livro de Leitura para Adultos, com o Golpe de 1964, foi jogado no Rio Meia Ponte e suas autoras interrogadas, perseguidas e exiladas do país. O livro produzido pelas autoras explicitava que, pelo processo educativo, democratizando a cultura, instrumentalizar-se-iam os homens, abrindo os canais de comunicação e possibilitando a análise da realidade social, para que esse próprio homem pudesse continuar a educar a si mesmo, no contato com a cultura e os outros homens, aprendendo a conduzir-se, a ser sujeito de si e da história, a se desalienar, enquanto pessoa humana, inserida no "trânsito", como diria Paulo Freire, e, ao fazê-lo - no seio das contradições internas e externas do sistema social - adquirir uma ferramenta, cujo "imenso poder [era] como uma arma invencível da Pré-revolução Brasileira" (MACIEL, 1963, p. 27).

\section{O CPC-GO e o Plano Nacional de Alfabetização}

Os vários movimentos populares em Goiás, entre eles o CPC, a Juventude Universitária Católica (JUC) e a Ação Popular (AP), eram apoiados e congregados pelo ICP do CERNE, e apoiavam-se mutuamente. Ou seja, os militantes dos movimentos de educação popular em Goiás trocavam 
ideias entre si, tanto nos encontros estaduais e nacionais, quanto através da participação em atividades e movimentos estudantis (UEE, UNE), religiosos (JUC), educacionais (MEB) ou de partidos políticos da época.

Uma nova geração de educadores-intelectuais se constituiu, os quais participavam ativamente de vários movimentos de alfabetização e cultura popular e pressionaram o MEC, no sentido de receberem apoio oficial e de se instituir uma coordenação nacional para as experiências de EDA: tanto no que se refere a dar unidade às ações dos movimentos de alfabetização e cultura popular, quanto a viabilizar o auxílio de verbas oficiais.

Diante das pressões, o MEC convocou o I Encontro Nacional de Alfabetização e Cultura Popular, realizado de 15 a 21 de setembro de 1963, em Recife, onde houve o lançamento oficial do Plano Nacional de Alfabetização (PNA), que previa a disseminação de programas de alfabetização pelo MEC e preocupava-se com a promoção da cultura popular. Foi escolhido o sistema Paulo Freire ${ }^{10}$ para ser utilizado pelo PNA.

A esse respeito o Jornal 4 Poder (14/07/1963, p. 1) de Goiânia divulgou reportagem sobre a taxa de escolarização no Brasil, o analfabetismo, e reunião do MEC com os movimentos de educação popular:

O novo Ministro da Educação, Deputado Paulo de Tarso [... realizou] em Brasília, uma reunião dos institutos de cultura popular, de todos os Estados, no sentido de promover um esforço comum para superar a falta de escolas e provocar a queda do elevado índice de analfabetos. A primeira iniciativa foi a adoção do método do Professor Paulo Freire [...] que alfabetiza em 40 horas. No Distrito Federal, já foram abertas inscrições [...] e, em agosto próximo, o método será aplicado nos bairros de Goiânia e interior do Estado.

Em Goiás, como parte preparatória para implantação do PNA, a equipe do ICP e do CPC, com a colaboração da Campanha Estudantil de Alfabetização de Goiás, realizou em julho e agosto de 1963, segundo o Jornal $4^{\circ}$ Poder (1\%/9/1963), uma pesquisa nos bairros e vilas da capital goiana, para levantar dados do universo vocabular e do nível intelectual da população - o número e localização dos analfabetos, o interesse em alfabetizar-se, o lazer, a profissão, a religião e o grau de politização etc. - com vistas à composição de turmas de alfabetização e escolha das palavras geradoras.

O resultado da pesquisa apontou que havia $56 \%$ de analfabetos, dos quais $79 \%$ se interessavam em alfabetizar-se. Diante dos resultados obtidos com a pesquisa o ICP/CPC abriria 10 novos cursos em Goiânia. A preparação do PNA contou com a participação de estudantes, sindicatos, educadores, profissionais liberais e representantes dos movimentos de educação e cultura 
popular, mas teve vida curta, sendo interrompido alguns meses depois pelo golpe militar.

A montagem do PNA ocorreu em paralelo à coordenação dos movimentos de cultura popular; em janeiro de 1964 ocorreu o Seminário Nacional com representantes dos principais movimentos de cada Estado (MEB, CPCs e MCPs), criando-se a Comissão Nacional de Cultura Popular, a qual foi reconhecida pelo MEC e funcionou no período de janeiro a março de 1964, mas foi dissolvida com o Golpe.

No dia do golpe militar de 1964, conforme nos afirmou José Pereira Peixoto Filho ${ }^{11}$ em entrevista, vários estudantes, professores, profissionais liberais, entre outros, estavam no Teatro Emergência, em Goiânia, discutindo a implantação do PNA em Goiás, quando contaram com a presença de Paulo Freire, que fez o encerramento do encontro. Posteriormente ele foi preso e exilado. A extinção do PNA foi uma das primeiras ações do governo militar.

\section{CONSIDERAÇÕES FINAIS}

Para os militantes que atuaram no CPC-GO e demais movimentos de educação popular, especialmente estudantes, educadores populares e profissionais liberais, a luta pelas reformas de base trazia dentro de si a convocação para uma mudança de estruturas, o que era veemente defendido. Daí a importância da alfabetização do povo, especialmente de adultos pobres, com tomada de consciência, sobretudo a respeito da sua situação econômica e social e da situação do país. Era uma proposta solidária com os interesses e a luta dos trabalhadores pela mudança das condições de existência vigentes, o que gerou, entre outros aspectos, a aliança estudantes-camponeses, inclusive em Goiás. Embora esses movimentos tenham sido ceifados pela ditadura militar pós-1964, muitos de seus ideais permaneceram no seio da educação popular e da educação de jovens e adultos deste país.

THE EXPERIENCE OF POPULAR EDUCATION AT THE GOIÁS CENTER FOR POPULAR CULTURE

ABSTRACT:This article discusses the involvement of the Goiás Center for Popular Culture in adult education in the 1960s. This was a popular education movement, organized by the National Union of Students, engaging high school and university students, intellectuals and artists in cultural awareness activities and in adult education in the State of Goiás. The study shows how these militants in Goiás were influenced by the Recife Popular Culture Movement in terms of adult literacy, resulting in the preparation of a book entitled Leitura para Adultos (Readings for Adults). The text is 
based on doctoral research, including documental analysis, interviews, testimonies and reports from militants of that period.

KeYwords: Goiás Center for Popular Education. Popular Education. Youth and Adult Education.

\section{NOTAS}

1. Este texto é resultado da tese de doutorado de Rodrigues (2008).

2. Diálogo tomado como encontro dos homens mediatizados pelo mundo, para pronunciá-lo, e que envolve ação e reflexão, a práxis, sob pena de tornar-se ativismo ou discurso vazio (FREIRE, 1962).

3. Segundo Alda Maria Borges Cunha, em entrevista em vídeo, concedida a Maria Emilia de Castro Rodrigues, sobre o Movimento de Educação de Base em Goiás, disponível no Museu Virtual da Educação em Goiás, no link Memória Viva: "todo o prédio da UCG era ali onde hoje é a Filosofia (FIT) e funcionam as Licenciaturas. [...] da Catedral até o Setor Universitário era todinho chão, terra batida, área de posse urbana [...] dos dois lados, casebres... E era dentro deste espaço que a gente se movimentava fazendo [...] alfabetização de adultos" (22/02/2002).

4. Entrevista concedida a Maria Emilia de Castro Rodrigues, quando da escrita da tese de doutorado.

5. A equipe interdisciplinar do SEC, juntamente com Paulo Freire, aprofundou a fundamentação teórica do método, dando origem ao Sistema Paulo Freire. No artigo de Jarbas Maciel, denominado "A Fundamentação Teórica do Sistema Paulo Freire de Educação", afirmava que tal Sistema compreendia a alfabetização infantil; a alfabetização de adultos; o ciclo primário rápido, que contava inclusive com a leitura de antologias com noções básicas de legislação e trabalho, geografia econômica, economia, sindicalismo, assuntos técnicos ligados às profissões, arte popular, folclore, Ciências do Homem, formação de bibliotecas populares, entre outras; a quarta etapa do Sistema consistia na experiência da Universidade Popular, por meio da extensão universitária cultural, envolvendo os níveis secundário, pré-universitário e universitário; a quinta etapa envolveria a formação no Instituto de Ciências do Homem, da Universidade do Recife; e a última etapa do Sistema, ainda em esboço, desembocaria no Centro de Estudos Internacionais (CEI) da Universidade do Recife, órgão criado em 1963, com vistas à"intensa transação com os países subdesenvolvidos, num esforço de integração do chamado terceiro mundo" (MACIEL, 1963, p. 7).

6. Sobre esses critérios afirma Maciel (1963b, p. 56): “Hoje, nós vemos que [...] estão contidos no critério semiótico: a melhor palavra geradora é aquela que reúne em si a maior'percentagem' possível dos critérios sintático (possibilidade ou riqueza fonêmica, grau de'dificuldade fonêmica complexa, de'manipulabilidade' dos conjuntos de sinais, as sílabas etc.), semântico (maior ou menor 'intensidade' do vínculo entre a palavra e 
o ser que a designa, maior ou menor adequação entre palavra e ser designado etc.) e pragmático (maior ou menor teor de conscientização que a palavra traz em potencial, ou conjunto de reações socioculturais que a palavra gera na pessoa ou grupo que a utiliza)". Fundamentação teórica que envolvia, entre outros campos, investigações ligadas à Lógica Moderna, à Teoria do Conhecimento, à Teoria da Comunicação, à Sociologia e à Antropologia Cultural.

7.É pelo trabalho que, ontologicamente, o homem tem a possibilidade de humanizar-se, como expressão da capacidade criadora e transformadora do ser humano, que na relação com os outros homens e com a natureza, produz cultura, faz história e, ao fazê-lo, transforma-se. O trabalho está na base da sociabilidade humana, pois é elemento de constituição do ser humano enquanto ser humanizado, expressão da práxis; é por ele que os homens se relacionam com o mundo (natureza e os homens) e podem intencionalmente transformá-lo.

8. Muitas críticas foram empreendidas à proposta freiriana - entre elas a efetivada por Vanilda Paiva (1984) -, algumas por desconhecerem ou realizarem uma leitura equivocada de sua produção, outras por considerarem que tomar a realidade social como ponto de partida para análise crítica é permanecer nela, aderido a ela, num basismo conteudista; ou ainda por interpretarem que, ao partir das palavras geradoras dos educandos, o educador negava-Ihes a possibilidade de acesso aos saberes elaborados cientificamente, inclusive retirando do professor o papel de educador, o que não coadunava com a prática freiriana. Contudo, Paulo Freire era enfático em dizer que não concordava com uma educação tradicional (depósito de conteúdos nos educandos); defendia uma pedagogia ativa em que o acesso a saberes significativos e seus instrumentos de análise crítica da realidade fossem trabalhados, dialogicamente.

9. Nas palavras da própria Alda (entrevista, 20/9/2006):"povo era uma grande categoria utilizada naquele momento pra designar um público, e não classe ou categoria social".

10. Este sistema desenvolvido no MCP e SEC de Pernambuco, e divulgado por todo o Brasil, havia sido implantado, por determinação do Ministro da Educação Paulo de Tarso, como projeto piloto em Brasília, Guanabara, Baixada Fluminense etc., tendo ocorrido em Goiânia, o curso de formação dos educadores que nele atuariam.

11. Entrevista concedida a Maria Emilia de Castro Rodrigues, durante a pesquisa da tese de doutorado.

\section{REFERÊNCIAS}

BORGES, Alda Maria; JAIME, Maria José. Livro de Leitura para adultos. Goiânia, GO: Centro Popular de Cultura de Goiás [1962].

CARDOSO, Aurenice. Conscientização e Alfabetização: uma visão prática do Sistema Paulo Freire. Estudos Universitários: Revista de Cultura da Universidade de Recife. v. 4, abr.-jun., 1963. Recife, PE: Universidade do Recife [Imprensa Universitária], 1963. 
CUNHA, Alda Maria Borges. Movimento de Educação de Base em Goiás. In: Memória Viva/ Museu Virtual da Educação em Goiás. Goiânia, 22/02/2002. Entrevista em vídeo (10 min.). Disponível em: <http://www.fe.ugf.com.br/museu/memoria_viva_meb_5. html>. Acesso em: 20 out. 2011.

. Movimento de Educação de Base em Goiás. Goiânia, 31/5/2001. Trabalho inédito (Palestra).

. Movimento de Educação de Base em Goiás nos anos 1960. Goiânia, 20/09/2006. Entrevista concedida a Maria Emilia de Castro Rodrigues. 52p. Digitado.

FREIRE, PAULO. Conscientização e alfabetização, uma nova visão do processo. Recife, PE, [1962] (Brochura, 41p.).

. Conscientização e alfabetização, uma nova visão do processo. Estudos Universitários. Revista de Cultura da Universidade de Recife. Recife, PE: Universidade do Recife. v. 4, 1963, p. 5-24.

Educação como Prática da Liberdade. Rio de Janeiro: Paz e Terra, 1967.

GÓES, Moacir de. De pé no chão também se aprende a ler (1961-1964) - uma escola democrática. Rio de Janeiro: Civilização Brasileira, 1980.

JORNAL 4 PODER. Ano 1, Goiânia, 14/7/1963, n. 44.

. Ano 1, Goiânia, 25/8/1963, n. 49.

. Ano 1, Goiânia, 1\%/9/1963, n. 50.

MACIEL, Jarbas. A fundamentação teórica do Sistema Paulo Freire de Educação. Recife, PE, s.n.,1963. (Brochura, 78 p.)

. A fundamentação teórica do Sistema Paulo Freire de Educação. Estudos Universitários. Revista de Cultura da Universidade de Recife. Recife, PE: Universidade do Recife, v. 4, 1963b.

PAIVA, Vanilda Pereira. Anotações para um estudo sobre populismo católico e educação no Brasil. In: PAIVA, Vanilda Pereira (Org.). Perspectivas e dilemas da Educação Popular. Rio de Janeiro: Edições Graal, 1984.

PEIXOTO FILHO, José Pereira. Movimentos de educação popular e o Movimento de Educação de Base em Goiás na década de 1960. Belo Horizonte, 8/8/2006. Entrevista concedida a Maria Emilia de Castro Rodrigues.

RAPÔSO, Maria da Conceição Brenha. Movimento de Educação de Base: discurso e prática - 1961-1967. São Luís, MA: UFMA/Secretaria de Educação, 1985.

RODRIGUES, Maria Emilia de Castro. A prática do professor na educação de adolescentes, jovens e adultos: a experiência do Projeto AJA de Goiânia-GO. Dissertação (Mestrado em Educação Brasileira) - Faculdade de Educação, Universidade Federal de Goiás, Goiânia, GO, 2000. 
. Enraizamento de esperança: as bases teóricas do Movimento de Educação de Base em Goiás. Tese (Doutorado em Educação Brasileira) - Faculdade de Educação, Universidade Federal de Goiás, Goiânia, GO, 2008. 314 p. Disponível em: http://fe.ufg. br/museu/memoria_viva_meb_5.html, vídeo, acesso em: 20/02/2007.

MARIA EMILIA de CAstro Rodrigues: Professora Doutora em Educação pela UFG. Atua como docente da Faculdade de Educação da Universidade Federal de Goiás, em Didática, Estágio e Educação de Jovens e Adultos. É membro do Fórum Goiano de Educação de Jovens e Adultos.

Email:me.castrorodrigues@gmail.com 